\title{
Prevalence and outcome of gestational diabetes mellitus in women from rural population attending antenatal clinic at a teaching hospital, Tamil Nadu, India
}

\author{
Vidhya Muthuramalingam ${ }^{1 *}$, Amar Nagesh Kumar ${ }^{2}$
}

\begin{abstract}
${ }^{1}$ Department of Obstetrics and Gynecology, Karpaga Vinayaga Institute of Medical Sciences and Research Centre, Madhuranthagam, Tamil Nadu, India

${ }^{2}$ Department of Biochemistry, Karpaga Vinayaga Institute of Medical Sciences and Research Centre, Madhuranthagam, Tamil Nadu, India
\end{abstract}

Received: 21 May 2020

Accepted: 30 June 2020

\section{*Correspondence:}

Dr. Vidhya Muthuramalingam,

E-mail: drvidhya2000@gmail.com

Copyright: (C) the author(s), publisher and licensee Medip Academy. This is an open-access article distributed under the terms of the Creative Commons Attribution Non-Commercial License, which permits unrestricted non-commercial use, distribution, and reproduction in any medium, provided the original work is properly cited.

\begin{abstract}
Background: Prevalence of gestational diabetes mellitus shows wide variation across our country. From the recent studies, it is observed that incidence of gestational diabetes mellitus in antenatal women is increasing globally and India is not an exception from this. Gestational diabetes mellitus should be considered as a serious risk factor for both mother and baby as it affects two generations by having chance of developing diabetes and its related complications in future.

Methods: A total of 585 pregnant women with 24 to 28 weeks of gestational age were recruited for the study. The study population was divided into four groups based on the age range; Group I include antenatal women with age $<20$ years, Group II includes antenatal women of age range 21-24 years, Group III includes antenatal women of age range 25-29 years, and Group IV includes antenatal women of age range $\geq 30$ years.

Results: In the present study GDM was diagnosed in 94 women among 585 antenatal women screened for GDM $(16.06 \%)$. Majority of the studied population are in the age range of $20-29$ years $(441 / 585,75.38 \%)$. The mean age of participants was 27.54 \pm 3.58 years (range 18-34 years). The prevalence of GDM was higher in the group of women aged $\geq 30$ years (Group IV) followed by $\leq 20$ years (Group I) $(23.21 \%$ and $15.62 \%$ respectively) compared to the groups II and III (14.78\% and $13.74 \%$ respectively). This observation was found to be statistically significant $(\mathrm{p}<0.001)$. Among 585 patients, delivery outcome was $100 \%$ successful, all delivered live babies, among them 64 patients delivered babies with macrosomia (11\%).

Conclusions: The study showed GDM prevalence of $16.06 \%$ from the neighboring rural villages attending our teaching hospital.
\end{abstract}

Keywords: Antenatal women, Gestational diabetes, Macrosomia, Pre-eclampsia, Prevalence

\section{INTRODUCTION}

Intolerance to glucose resulting in hyperglycaemia of variable degree during pregnancy is defined as a gestational diabetes mellitus (GDM). ${ }^{1,2}$ GDM should be considered as a serious risk factor for both mother and baby as it affects two generations by having chance of developing diabetes and its related complications in future. ${ }^{1-3}$ Prevalence of GDM shows wide variation across our country. ${ }^{1-3}$ Prevalence of GDM may range from 2.4 to $21 \%$ depending on factors like, the population studied and the diagnostic test employed., ${ }^{4,5}$ From the 
recent studies, it is observed that incidence of gestational diabetes mellitus (GDM) in antenatal women is increasing globally and India is not an exception. ${ }^{4-7}$ India is the diabetes capital of the world with 41 million Indians having diabetes. ${ }^{1,4}$ Every fifth diabetic in the world is an Indian. ${ }^{6,8}$ Therefore, prevalence of GDM in India cannot be underestimated. It is estimated by International Diabetes Federation (IDF) that 20.9 million or $16.2 \%$ of live births to women in 2015 had some form of hyperglycaemia in pregnancy. ${ }^{7,8}$ An estimated $85.1 \%$ of those cases were due to gestational diabetes 6-8. Therefore, the present study was undertaken to find out the prevalence and outcome of GDM among pregnant women from rural population of Kanchipuram district, Tamil Nadu region of India.

\section{METHODS}

Present study was carried out during November 2016 to December 2019 in a tertiary care hospital. The study was planned by department of obstetrics and gynecology as part of the activity of the 2016 World diabetes day. Assuming the prevalence with relative error of $20 \%$ at level of significance of $95 \%$, a sample of at least 550 subjects was required. Therefore, a total of 585 pregnant women were recruited for the study keeping in view of the drop outs from the study. Antenatal women with 24 to 28 weeks of gestational age who attended this study outpatient department of obstetrics and gynecology, during the study period were recruited for the study. The study population was divided into four groups based on the age range. Group I include antenatal women with age $<20$ years. Group II includes antenatal women of age range 21-24 years. Group III includes antenatal women of age range 25-29 years and Group IV includes antenatal women of age range $\geq 30$ years. Women who were known diabetics or who were suffering from any chronic illness were excluded. Before recruiting the subjects for the study, the women were sensitized about the study and informed consent was obtained from them.

The study was approved by the institutional ethics committee. A risk factor assessment questionnaire was administered. The proforma containing general information on demographic characteristics, parity and family history of diabetes and/or hypertension in first degree relatives were filled up for each woman. GDM was diagnosed based on the one-step universal screening with $75 \mathrm{~g}$ oral glucose challenge test and offered only to those who came fasting.

All participants were given $75 \mathrm{~g}$ of anhydrous glucose dissolved in $250 \mathrm{ml}$ of water was asked to drink in 3 to 5 minutes. Blood glucose levels were measured during fasting, one- and two-hours measurements were made subsequently. Results were interpreted and diagnosis was made as per World Health Organization (WHO) 2013 guidelines. ${ }^{9}$ They were further followed up till final delivery and posted for normal vaginal delivery, elective or emergency caesarean sections.

\section{Statistical analysis}

Descriptive statistics were used to describe the population. Statistical analysis was carried out using SPSS version 20. Categorical data are presented as n (\%). A p value of $<0.05$ was taken as statistically significant. The relationship between variables was explored using $2 \times 2$ contingency tables to determine chi squares and associated $\mathrm{p}$ values.

\section{RESULTS}

A total of 585 antenatal women were studied. All subjects underwent OGTT as per World Health Organization (2013) diagnostic criteria for GDM. Fasting, first hour and two-hour blood glucose values were checked after the ingestion of $75 \mathrm{~g}$ of glucose in fasting condition. In Group I (age <20 years) 32 patients were recruited and five of them were diagnosed as GDM (Table 1) based on their fasting blood sugar (FBS) and post prandial blood sugar (PPBS) values, which are $>120 \mathrm{mg} / \mathrm{dl}$, and $>153$ $\mathrm{mg} / \mathrm{dl}$ respectively. In Group II total 230 antenatal women were there (age 20-24 years) and 34 of them were diagnosed as GDM (Table 1) based on their fasting blood sugar (FBS) and post prandial blood sugar (PPBS) values, which are $>120 \mathrm{mg} / \mathrm{dl}$, and $>153 \mathrm{mg} / \mathrm{dl}$ respectively. Group III (age 25-29 years) contains 211 antenatal women and 29 of them were diagnosed as GDM (Table 1) based on their fasting blood sugar (FBS) and post prandial blood sugar (PPBS) values, which are $>120 \mathrm{mg} / \mathrm{dl}$, and >155 mg/dl respectively. In Group IV (age $\geq 30$ years) there are 112 patients and 26 of them were diagnosed as GDM (Table 1) based on their fasting blood sugar (FBS) and post prandial blood sugar (PPBS) values, which are $>120 \mathrm{mg} / \mathrm{dl}$, and $>155 \mathrm{mg} / \mathrm{dl}$ respectively (Table 1 ).

Table 1: Distribution of prevalence of GDM patients' age wise.

\begin{tabular}{|lll|}
\hline Age group & $\begin{array}{l}\text { No. of } \\
\text { patients } \\
\text { screened }\end{array}$ & $\begin{array}{l}\text { No. of } \\
\text { GDM } \\
\text { patients }\end{array}$ \\
\hline$<20$ years (Group I) & 32 & $5(15.62 \%)$ \\
\hline 20-24 years (Group II) & 230 & $34(14.78 \%)$ \\
\hline 25-29 years (Group III) & 211 & $29(13.74 \%)$ \\
\hline$\geq 30$ years (Group IV) & 112 & $26(23.21 \%)$ \\
\hline
\end{tabular}

In the present study GDM was diagnosed in 94 women among 585 antenatal women screened for GDM $(16.06 \%)$ (Table 2). Majority of the studied population are in the age range of $20-29$ years $(441 / 585,75.38 \%)$. The mean age of participants was $27.54 \pm 3.58$ years (range 18-34 years) (Table 2). The prevalence of GDM was higher in the group of women aged $\geq 30$ years (Group IV) followed by $\leq 20$ years (Group I) $(23.21 \%$ and $15.62 \%$ respectively) compared to the groups II and III $(14.78 \%$ and $13.74 \%$ respectively) (Figure 1$)$. This observation was found to be statistically significant $(\mathrm{p}<0.001)$. Population of primigravida women was $49.4 \%$ 
while that of multigravida was $50.6 \%$ (Table 2). Mode of delivery; 228 patients underwent normal vaginal delivery at term. 157 women were posted for elective caesarean sections at term, 185 women were posted for emergency caesarean sections at term due to various reasons and 15 patients underwent emergency caesarean section at preterm (Table 2).

Table 2: Summary of study characteristics, prevalence and outcome of antenatal women with GDM.

\begin{tabular}{|ll|}
\hline Parameter & Value \\
\hline Total antenatal patients assessed & $585(100 \%)$ \\
\hline Total no. of patients diagnosed as GDM & $94(16.06 \%)$ \\
\hline Mean age of the study group & $27.54 \pm 3.58$ \\
\hline Population of primigravida's & $289(49.4 \%)$ \\
\hline Population of multigravidas & $296(50.6 \%)$ \\
\hline Prevalence of macrosomia & $64(11 \%)$ \\
\hline Prevalence of preeclampsia & $11(2 \%)$ \\
\hline Incidence of normal vaginal delivery & $228(39 \%)$ \\
\hline Incidence of patients underwent LSCS & $357(61 \%)$ \\
\hline Incidence of favourable outcome & $585(100 \%)$ \\
\hline Patients received epidural anaesthesia & $18(3 \%)$ \\
\hline Patients received spinal anaesthesia & $567(97 \%)$ \\
\hline
\end{tabular}

Among 585 patients, delivery outcome was $100 \%$ successful, all delivered live babies, among them 64 patients delivered babies with macrosomia (11\%) (Table 2). Spinal anaesthesia was given for $97 \%$ of the caesarean delivery, whereas $3 \%$ of patients received epidural anaesthesia (Table 2).

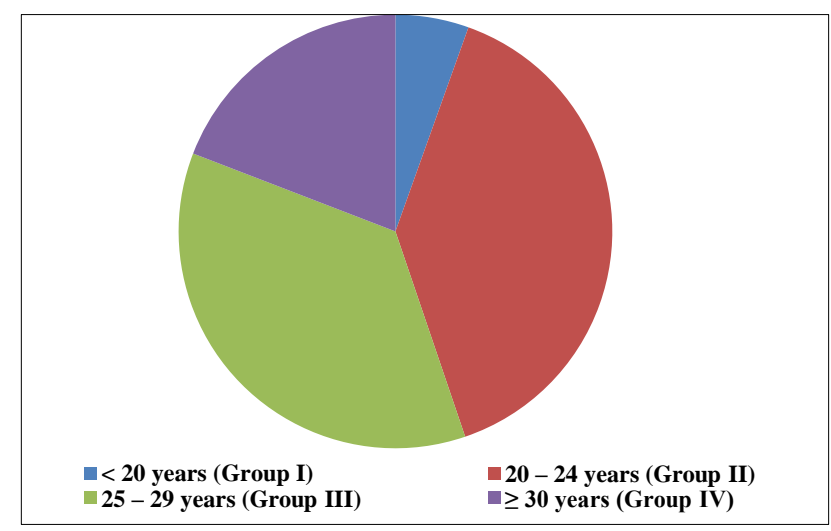

Figure 1: Age wise distribution of studied subjects.

\section{DISCUSSION}

Pregnant women attending antenatal clinics outpatient department of this study institution were selected and screened for GDM as per WHO 2013 guidelines by $75 \mathrm{~g}$ oral glucose challenging test. ${ }^{9,10}$ All the patients were screened for GDM as a routine protocol of the institution. To find out the prevalence of GDM in the rural population of our area present study was planned. ${ }^{11-13}$ The study included screening of 585 antenatal women for
GDM and closely followed up till the delivery to monitor the outcome in GDM patients.

In this study the prevalence of GDM is $16.06 \%$ in rural population of our area. Further, the study population was categorized into four groups based on their age and the prevalence in individual group was also calculated (Table 1). Highest rate of GDM prevalence was observed in Group IV with $23.21 \%$. Surprisingly second highest rate of GDM prevalence was observed in Group I antenatal women with $15.62 \%$. This may be because of over eating and sedentary life of now a day adolescent age antenatal woman. The prevalence rate of GDM in Group II and Group III is $14.78 \%$ and $13.74 \%$ respectively (Table 1 and Figure 2).

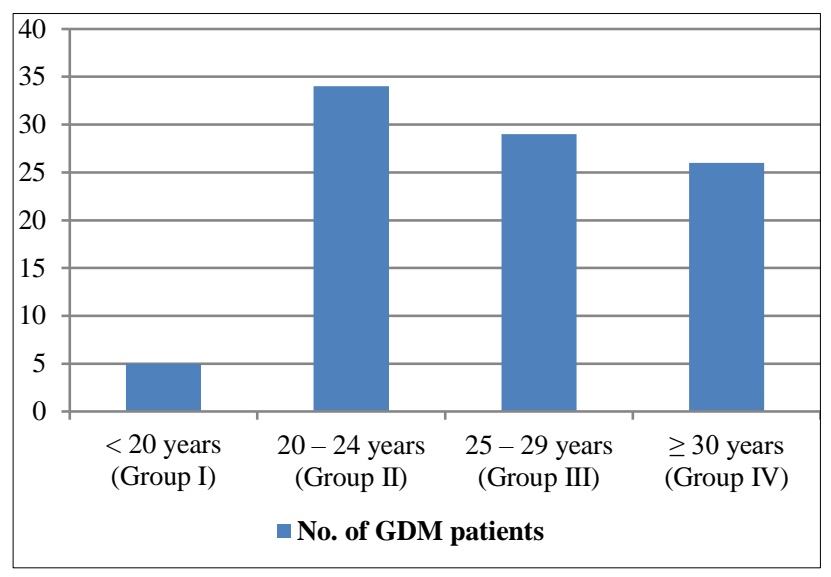

Figure 2: Comparison of prevalence of GDM among the four studied groups.

A community-based study conducted in 2004 of 853 pregnant women in Homagama $\mathrm{MOH}$ area reported a rate of $8.4 \%$ (75 g OGTT and 1999 WHO criteria) with the rate increasing with maternal age $(<25$ years $3 \%, 25-35$ years $9.6 \%$ and 35 years $15.9 \%$ ) and the age standardized prevalence was $10.3 \% .{ }^{14}$ The present study shows over all GDM prevalence of $16.06 \%$ in our rural population of Kanchipuram district that alarms the increasing incidence of GDM in India. The rise of incidence of GDM is two times that of prevalence of GDM in Homagama $\mathrm{MOH}$ area, study done in Colombo in $2004 .{ }^{14}$ Similarly, Indian origin studies if authors observe, prevalence of GDM of $18.9 \%$ was reported from an antenatal clinic of a Government Maternity Hospital, Chennai among 891 pregnant women in their second or third trimester (OGTT and WHO 1999 criteria) by Seshiah V in the same year 2004. ${ }^{11,15}$

A study carried out among 4151, 3960 and 3945 pregnant women in urban, semi urban and rural areas, respectively in South India (Tamil Nadu), reported $17.8 \%$ in urban, $13.8 \%$ in semi urban and $9.9 \%$ in rural areas. ${ }^{13}$ Several studies have identified increasing maternal BMI as a significant risk factor for GDM. ${ }^{15-17} \mathrm{BMI}$, family history of diabetes mellitus and age 35 years were found to be independent risk factors for GDM in other studies. ${ }^{18-20}$ 
Findings from this study were compatible with these findings.

The uniqueness of the study is prevalence of GDM rate is very high in Group I category compared to the Group II and Group III patients.

All most all the studies have reported that as the age increases the rate of GDM prevalence is increasing. But in this study the Group I ( $<20$ years) being adolescent age group reported second highest rate of prevalence of GDM in our population which is to be noted carefully.

\section{CONCLUSION}

The study showed GDM prevalence of $16.06 \%$ from the neighbouring rural villages attending our teaching hospital. As discussed in this article GDM should not be underestimated because its co-morbidity among pregnant population with global prevalence rate of 16 to $20 \%$ throwing challenge to the present-day women. Hence, efforts should be directed to diagnose GDM at an early stage and take preventive measures for its further progression to type 2 diabetes. It is no exaggeration to state that India may become the future Diabetic capital of world, as proportionate increase in the prevalence rate of GDM and associated complications are increasing year over year. Therefore, it is better to screen every antenatal woman during their visits for regular check-up for early detection and management of GDM.

\section{ACKNOWLEDGMENTS}

The authors would like to thank Dr Regupathy Annamalai, Managing Director of Karpaga Vinayaga Institute of Medical Sciences and Research Centre for giving permission to carry out this project. The authors also would like to thank professor and HOD of department of obstetrics and gynecology of KIMS and $\mathrm{RC}$ for her support and cooperation in accomplishing this project.

Funding: No funding sources

Conflict of interest: None declared

Ethical approval: The study was approved by the Institutional Ethics Committee

\section{REFERENCES}

1. Joshi SR, Parikh RM. India - diabetes capital of the world: now heading towards hypertension. J Assoc Physicians India. 2007;55:323-4.

2. Gasim T. Gestational diabetes mellitus: maternal and perinatal outcomes in 220 Saudi women. Oman Med J. 2012;27(2):140.

3. Wendland EM, Torloni MR, Falavigna M, Trujillo J, Dode MA, Campos MA, et al. Gestational diabetes and pregnancy outcomes-a systematic review of the World Health Organization (WHO) and the International Association of Diabetes in Pregnancy study groups (IADPSG) diagnostic criteria. BMC Pregnancy Childbirth. 2012;12(1):23.

4. Kanguru L, Bezawada N, Hussein J, Bell J. The burden of diabetes mellitus during pregnancy in lowand middle-income countries: a systematic review. Glob Health Action. 2014;7(1):23987.

5. Carr DB, Utzschneider KM, Hull RL, Tong J, Wallace TM, Kodama K, et al. Gestational diabetes mellitus increases the risk of cardiovascular disease in women with a family history of type 2 diabetes. Diabetes Care. 2006;29(9):2078-83.

6. Nagy K, Pomucz J, Varga R, Szabo E, Soltesz G. Anthropometric data, fetal and neonatal complications in infants of diabetic mothers. Results of a 10 year retrospective study. Orv Hetil. 2013;154(5):172-7.

7. Shah BR, Retnakaran R, Booth GL. Increased risk of cardiovascular disease in young women following gestational diabetes mellitus. Diabetes Care. 2008;31(8):1668-9.

8. Retnakaran R, Shah BR. Mild glucose intolerance in pregnancy and risk of cardiovascular disease: a population-based cohort study. Can Med Assoc J. 2009;181(6-7):371-6.

9. World Health Organization. Diagnostic criteria and classification of hyperglycaemia first detected in pregnancy. Diabetes Res Clin Pract. 2014;37(1):S1480.

10. Siribaddana SH, Deshabandu R, Rajapakse D, Silva K, Fernando DJ. The prevalence of gestational diabetes in a Sri Lankan antenatal clinic. Ceylon Med J. 1998;43:88-91.

11. Seshiah V, Balaji V, Balaji MS, Sanjeevi CB, Green A. Gestational diabetes mellitus in India. J Assoc Physicians India. 2004;52:707-11.

12. Ginige PS. Prevalence and pregnancy outcome of gestational diabetes mellitus (GDM) in Homagama DDHS area and validation of selected screening methods to detect GDM. Post Graduate Institute of Medicine, University of Colombo; 2004.

13. Seshiah V, Balaji V, Balaji MS, Paneerselvam A, Arthi T, Thamizharasi M, et al. Prevalence of gestational diabetes mellitus in South India (Tamil Nadu) - a community-based study. J Assoc Physicians India. 2008;56:329-33.

14. Mahalakshmi MM, Bhavadharini B, Maheswari Kumar RM, Shah SS, Bridgette A, Choudhury M, et al. Clinical profile, outcomes, and progression to type 2 diabetes among Indian women with gestational diabetes mellitus seen at a diabetes center in south India. Indian $\mathbf{J}$ Endocrinol Metab. 2014;18:400-6.

15. Padmanabhan S, Wagstaff A, Tung V, Chan YF, Bartlett A, Lau SM. Increase in body mass index during pregnancy and risk of gestational diabetes. Diabetes Res Clin Pract. 2014;106:79-82.

16. Flores-Padilla L, Solorio-Páez IC, Melo-Rey ML, Trejo-Franco J. Pregnancy and obesity: risk of developing gestational diabetes in the northern 
border area of Mexico. Gac Med Mex. 2014;150:738.

17. Duman NM. Frequency of gestational diabetes mellitus and the associated risk factors. Pak J Med Sci. 2015;31:194-7.

18. Khan R, Ali K, Khan Z. Socio-demographic risk factors of gestational diabetes mellitus. Pak J Med Sci. 2013;29:843-6.

19. Martin KE, Grivell RM, Yelland LN, Dodd JM. The influence of maternal BMI and gestational diabetes on pregnancy outcome. Diabetes Res Clin Pract. 2015;108:508-13.
20. Beucher G, Viaris de Lesegno B, Dreyfus M. Maternal outcome of gestational diabetes mellitus. Diabetes Metab. 2010;36(6 Pt 2):522-37.

Cite this article as: Muthuramalingam V, Kumar AN. Prevalence and outcome of gestational diabetes mellitus in women from rural population attending antenatal clinic at a teaching hospital, Tamil Nadu, India. Int J Reprod Contracept Obstet Gynecol 2020;9:3260-4. 